\title{
LA ADMINISTRACIÓN, UNA FUNCIÓN EN PROCESO DE CAMBIO
}

\author{
JESÚS ANTONIO AVENDAÑO*
}

\section{RESUMEN}

El autor explora brevemente los aspectos históricos y contextuales, claves de la Administración hasta obtener las características actuales de ésta, de la gerencia y de la formación dentro de un marco interdisciplinario, transdisciplinario y multidisciplinario.

Palabras clave: reseña histórica, interaisciplinaridad, transdisciplinaridad, multidisciplinaridad, formación por competencias.

* Coordinador del Área de Administración. Profesor Facultad de Administración de Empresas, Universidad de La Salle. E-mail: aavendano@jupiter.lasalle.edu.co

Fecha de recepción: septiembre 2004

Fecha de aprobación: enero de 2005 


\section{ADMINISTRATION, A FUNCTION IN A CHANGING PROCESS}

\section{ABSTRACT}

The author explores the main historical and contextual aspects of the Administration to obtain the current characteristics of it, of management and those of the formation inside an interdisciplinary, trans-disciplinary and multidisciplinary frame.

Key words: historic description, inter-disciplinarity, trans-disciplinarity and multi-disciplinarity, learning for skills. 


\section{Introducción}

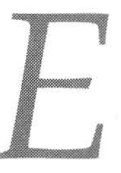

ste artículo resume las reflexiones del autor sobre el desarrollo de la Administración desde lo simple a lo complejo, en las diferentes etapas históricas, hasta abordar sus retos actuales, en un mundo globalizado, donde el conocimiento significativo requiere ser instrumentalizado a favor de la acertada toma de decisiones en contexto que permitan la sostenibilidad de las organizaciones a través de una adecuada gestión administrativa que no sólo permita la supervivencia sino su desarrollo continuo, en un mundo y una época cada vez más compleja.

\section{Antigüedad}

La Administración es tan antigua como el hombre mismo. Alrededor de 10.000 a. de J.C., cercanamente posterior a la retirada de los glaciares hacia el norte, cuando los grupos familiares al principio y luego grupos convertidos en tribus unieron sus esfuerzos para auxiliarse mutuamente, ya sea por su debilidad e indefensión natural frente a sus enemigos, o por la lucha de supervivencia nómada a través de la cacería y de lo que la naturaleza les proporcionaba a manera de autoconsumo sin excedentes, para lo cual uniendo el instinto y la experiencia fueron adelantando de manera natural, destrezas tácticas y estratégicas, los patriarcas mediante su experiencia avanzaron en el hábito de la previsión; fueron esbozando rústicas prácticas de jerarquía, autoridad, mando, poder y división natural (sexo y edad) y social del trabajo (caza y pesca, agricultura, pastoreo y oficios) desarrollaron instrumentos de trabajo y se empezaron a producir excedentes, con éstos surge el intercambio o trueque que convierte la propiedad familiar en propiedad privada.

«En algunos de los más antiguos documentos del mundo, encontrados en la civilización sumeria de hace cinco mil años, hay evidencias de prácticas de control administrativo. Los sacerdotes de los templos sumerios a través de su vasto sistema tributario recogieron y administraron considerables cantidades 
de bienes materiales, incluyendo hatos, rebaños, rentas y propiedades... Debido a que estos pueblos sumerios reconocieron la necesidad de este control administrativo, no es sorprendente que los documentos escritos más antiguos del mundo sean las cuentas de sus inventarios de hace cinco mil años. Es muy probable que las necesidades administrativas de esta antigua civilización hayan conducido a la invención de la escritura sumeria. El estímulo por supuesto fue económico; y aunque desarrollado por los sacerdotes, el primer uso de la escritura fue con propósitos de control administrativo y no para fines litúrgicos» (George, 1974).

Más adelante, después de que los clanes y las tribus entablaron luchas por defensa y expansión de territorios, entonces surge el Estado incipiente (edad de los metales), que incorpora en mayor magnitud las habilidades antes descritas y en su arrollador avance de fuerza y dominio esclavista (producción generalizada de excedente económico, surgen los mercaderes y el comercio, aparecen sistemas de almacenamiento y distribución de mercancías, aparece el trabajo a destajo y a domicilio, se inventa la moneda metálica y con ella los albores del depósito y crédito bancario), entonces emerge la necesidad de control sobre sus dominios (colonias y esclavos), pasando del centralismo al descentralismo, a la delegación y de paso la apropiación de las técnicas, la organización social y económica de los pueblos que iban conquistando.

La construcción de pirámides como la de Cheops que cubre trece acres y contiene 2’300.000 bloques de piedra, pesando cada una un promedio de 1.5 y 2 toneladas con una fuerza de trabajo de 100.000 hombres laborando durante veinte años.

"Cuando consideramos la planificación, organización y control que se han debido ejercer en esta empresa, está claro que los conceptos y técnicas administrativas que conocemos no nacieron en el siglo XX» (George, 1974: 4).

Los antiguos filósofos chinos fueron los primeros en reconocer la necesidad de la selección de personal y el staff. Las enseñanzas de Sun Tsu que reúne la esencia del saber estratégico que sigue aplicándose hoy en muy diversos aspectos de la vida personal, familiar y profesional sobre planificación y dirección en su libro El arte de la guerra que postula el arte de triunfar en la guerra o en la cotidianidad, paradójicamente basado en la máxima de vencer sin batallar, que han sido identificadas en el auge comercial de los dragones de oriente, es hoy día de obligatorio conocimiento por parte de los ejecutivos.

En medio de esta evolución histórica económica, política y social, van engendrándose difusamente los conceptos de administración y de administra- 
dores. Es así como Aristóteles en su obra La política, libro primero, capítulo I, II y III, se esfuerza en diferenciar la administración doméstica de la adquisición de la propiedad y de la administración del Estado:

«No han tenido razón, pues, los autores para afirmar que los caracteres del rey, magistrado, padre de familia y dueño se confunden. Esto equivale a suponer que toda la diferencia entre éstos no consiste sino en el más y el menos, sin ser específica; que un pequeño número de administradores constituiría el dueño, un número mayor el de padre de familia, uno más grande el magistrado o el rey; es de suponer, en fin, que una gran familia es en absoluto un pequeño Estado. Estos autores añaden, por lo que hace al magistrado $y$ al rey que el poder del uno es personal e independiente, y que el otro es en parte jefe y en parte súbdito, sirviéndose de las definiciones mismas de su pretendida ciencia. Toda esta teoría es falsa...»

Continúa en el libro II de la citada obra:

«...Tenemos primero la autoridad del señor, después la autoridad conyugal, ya que la lengua griega no tiene palabra particular para expresar esta relación del hombre a la mujer; y, en fin, la generación de los hijos, idea para la que tampoco hay una palabra especial. A estos tres elementos, que acabamos de enumerar, podría añadirse un cuarto, que ciertos autores confunden con la administración doméstica, y que, según otros, es cuando menos un ramo muy importante de ella; la llamada adquisición de la propiedad, que también nosotros estudiaremos».

«Por otro lado, la propiedad es una parte integrante de la familia; y la ciencia de la posesión forma igualmente parte de la ciencia doméstica, puesto que sin las cosas de primera necesidad los hombres no podrían vivir y menos vivir dichosos».
La Administración es tan antigua como el hombre mismo. Alrededor de 10.000 a. de J.C., cercanamente posterior a la retirada de los glaciares hacia el norte, cuando los grupos familiares al principio y luego grupos convertidos en tribus unieron sus esfuerzos para auxiliarse mutuamente ya sea por su debilidad e indefensión natural frente a sus enemigos o por la lucha de supervivencia nómada. 
«Saber emplear a los esclavos constituye la ciencia del señor, que lo es, no tanto porque posee esclavos, cuanto porque se sirve de ellos. Esta ciencia, en verdad, no es muy extensa ni tampoco muy elevada; consiste tan sólo en saber mandar lo que los esclavos deben saber hacer. $\mathrm{Y}$ así, tan pronto como puede el señor ahorrarse este trabajo, cede su puesto a un mayordomo para consagrarse él a la vida política o a la filosofía». (El subrayado es del autor del presente artículo).

Los principios de producción máxima mediante el uso de métodos uniformes a tiempos estipulados, donde el trabajo repetitivo se estableció musicalmente, la flauta, el clarinete y el tambor gobernaron movimientos, con sonidos y frecuencias para cada tarea y para cada operación, fue impuesto por los griegos.

«Mirando a la totalidad del continuum del pensamiento administrativo durante este período antiguo de la historia, podemos concluir que la administración se apoyó estrictamente sobre una base de ensayo-y-error, con poca o ninguna teoría y virtualmente sin intercambio de ideas y prácticas».

«En general, parece que los principios administrativos empleados nacieron de la necesidad de alcanzar metas propuestas, y que esos principios fueron descubiertos una y otra vez por numerosos individuos en la historia, en la medida en que ellos intentaban alcanzar objetivos deseados.

De este modo, en esos tiempos antiguos, el pensamiento administrativo existió, pero solamente en un estado nebuloso y no sofisticado. La administración como un proceso separado no fue verbalizada, sino hasta Platón y Sócrates. Aún entonces, sin embargo, los principios no fueron unificados en un esquema de pensamiento administrativo, ni hay evidencias de alguna cronología de variadas técnicas administrativas construidas sobre las previamente concebidas» (George, 1974: 26).

\section{Feudalismo}

Con la caída del imperio Romano en el siglo V, se abre paso el feudalismo en la época de los reinos medievales europeos como los francos y los germanos. La base económica era el feudo como unidad cerrada cuya actividad principal era la agricultura, la forma de explotación era la renta de la tierra en especie, en trabajo y en dinero. La producción de los artesanos especializados se realizó fuera de los feudos, en los burgos, que son el antecedente de las ciudades. Los artesanos se agrupan en gremios y los 
comerciantes en guildas para favorecer el desarrollo de la producción y el comercio.

Es así como la producción artesanal propicia el desarrollo del comercio y la formación de mercados locales, regionales y finalmente nacionales. La producción mercantil penetró al feudo cuando el señor feudal exigía a los siervos el pago de la renta en dinero, lo cual hizo que éstos vendieran su producción en las nacientes ciudades. Durante el medioevo no se escribió virtualmente ningún libro concerniente a conceptos de administración pues manejar un feudo fue descargado sobre uno de los súbditos, mientras que el instruido señor se mostraba más interesado en actividades más importantes como cazar, montar a caballo y jugar. No obstante, el profesor Pacioli (1494) recopila y describe el sistema contable de la partida doble empleado en Venecia usados en el libro mayor de los banqueros desde 1340, así como también registros de contabilidad de costos encontrados en los libros de contabilidad de Francisco Di Marco en 1395, cuya vigencia continúa hasta nuestros días proporcionando elementos para el control y la toma de decisiones.

\section{Edad moderna}

Surge así desde el siglo XVI hasta nuestros días el capitalismo, que representa las inversiones en medios de producción, en la compra de fuerza de trabajo, en la producción generalizada de mercancías que requiere de la existencia del mercado y de una economía monetaria para su funcionamiento, cuya finalidad es la obtención de ganancias para quien invierte.

Aportes como los de Tomás Moro, Robert Owen, Nicolás Maquiavelo, James Steuart, Adam Smith, René Descartes, entre otros, fueron semilla multidisciplinaria de los principios administrativos. 
Charles Babbage (1832), matemático, científico, inventor y escritor, más que ningún otro autor, contribuyó al inicio y desarrollo del enfoque científico del estudio de la administración. Fue consciente y tuvo fe en que los principios de la organización como procesos científicos de pensamiento eran aplicables a cualquier campo en donde la coordinación del esfuerzo humano fuera esencial para el logro de un objetivo común. Babbage había tropezado más de medio siglo antes que Taylor con principios generales aplicables a la fabricación de productos por máquinas como producto de sus visitas a las fábricas y talleres durante 10 años, cuyo análisis fue publicado en The Economy of Machinery and Manufacturers en 1832.

«... En las primeras etapas de la economía mecanizada, el principal país, el clásico ejemplo de desarrollo industrial fue Gran Bretaña. Y como subrayó uno de los historiadores contemporáneos, una alegre incapacidad en aprehender ideas generales se da entre la gente de la Gran Bretaña y su impacto perturbador... Gran Bretaña es el único país del mundo donde el título de catedrático es un término de reconvención...» (Urwick \& Brech.. 1984).

En el otro lado del océano, al final de la guerra civil, comenzó un clima industrial favorable para los negocios americanos, aumentó la población en el oeste, la industria se expandió, se separó la administración de la mano de obra, creció la clase administrativa, se implementaron sistemas administrativos integrales, líderes como Towne y Metcalfe pedían que los administradores formaran organizaciones, publicaran revistas e intercambiaran sus puntos de vista. En este ambiente emergió Frederick Winslow Taylor.

\section{Administración estructurada}

Para Taylor los administradores deberían abandonar el concepto militarizado del «hombre del látigo» y despojar a las decisiones administrativas de las premoniciones, intuición, experiencias anteriores o en evaluaciones a ojo de buen cubero, para desarrollar una nueva filosofía y un nuevo enfoque de la administración consistente en una visión más comprensiva del trabajo incorporando elementos de planificación, organización y control.

«La figura y la obra de Frederick Winslow Taylor han sido, y son aún hoy, origen de sentimientos encontrados. Pero es justo reconocer que, en términos de letra impresa, los juicios desfavorables y críticos superan apreciablemente a los elogios... La American Federation of Labour llegó a afirmar que 
el sistema inhumano y asqueroso (de Taylor) reduce a los seres humanos al estado de simples máquinas». (Taylor, 1984).

Es importante señalar que era una época de grandes conflictos sociales producto de una enconada lucha de clases producto de una sobre explotación del capitalismo «salvaje», por lo que cualquier intento por innovar producía sensibles suspicacias en los actores del conflicto.

Los aportes de Taylor fueron el inicio de la sistematización de una serie de principios que le dan fundamento a la administración, sacándola de la base de ensayoy-error empírico en que tradicionalmente se la tenía, es decir, a partir de Taylor ya no se puede confiar en la simple intuición artística o el ojo de buen cubero.

«La administración, a pesar de su importancia para el hombre, es una de las más ubicuas y difusas funciones en todas las sociedades, encontrándose en los hogares, iglesias, gobierno y empresas económicas de todos los pueblos. Es y siempre ha sido una poderosa herramienta de los líderes. De hecho, todos los líderes verdaderamente importantes de la historia fueron administradores, ora conduciendo exploraciones y guerras, manejando en fin las empresas de otros hombres» (George, 1974).

Supera también el sentido de simple técnica, pues sus decisiones no se basan en procedimientos meramente mecanicistas, convirtiéndose en una ciencia multidisciplinaria, interdisciplinaria y transdisciplinaria que busca el avance del conocimiento y que como profesión está relacionada con el logro de objetivos prácticos.

Multidisciplinaria, porque ha venido dialogando y enriqueciéndose con ciencias sociales como la economía, la psicología, la sociología, la antropología, el derecho, entre otros, con las ciencias exactas como la matemática y con disciplinas técnicas como la contabilidad, la ergonomía, la ingeniería, la cibernética.

Interdisciplinaria, porque sin desconocer sus límites busca factores de unidad entre los diversos saberes en cuanto al objeto, el método y al lenguaje.

Transdisciplinaria, porque permea otros campos del saber y de la acción.

Es importante señalar que cada escuela, tendencia o aporte está determinado dentro de un contexto histórico específico que enriquece el avance del conocimiento en forma parcial o total. 
Los cambios tecnológicos, socioculturales, políticos y económicos que se han ido produciendo en las últimas décadas, tienen un profundo impacto en el funcionamiento organizativo, los principios que regían la gestión se han transformado en forma radical progresiva y continua; en tiempos críticos, la técnica acostumbrada de planificación que supone un mundo ordenado y continuo, no sirve de nada. El ambiente de los negocios ahora es incierto, el entorno actual ha propiciado cambios en las ventajas competitivas y comparativas de las organizaciones, tanto internas como externas, para alcanzar, sostener y mejorar su posición. Es preciso comprender que el conocimiento es la clave de la prosperidad y por lo tanto el trabajador intelectual es el recurso más importante de la administración, es decir, estamos ubicados en una sociedad del conocimiento donde las organizaciones deben lograr ventajas competitivas como habilidades, recursos, atributos, conocimientos, entre otros, de que disponen las organizaciones, y de la que carecen sus competidores o disponen en menor medida, y que hacen posible el logro de unos rendimientos superiores, haciendo que el entorno y competitividad caminen por el mismo sendero. A su vez, el aumento de exigencias por parte de los clientes con respecto de las empresas, habiéndose pasado de mercados de compradores (mayor demanda que oferta) a mercados de vendedores (mayor oferta que demanda), lo que ha propiciado un fortalecimiento de la posición que ostentan los clientes en el mercado. El acortamiento del ciclo de vida de los productos en la lucha por hacerlo obsoleto antes de que la competencia lo haga, lleva a las empresas a recuperar la inversión en períodos de tiempo más cortos, desencadenando una política de alianzas entre competidores para disminuir inversiones y amortiguar riesgos. La imperiosa necesidad de incrementar la calidad en los productos y servicios como exigencia del mercado sin la cual ya no es posible competir y mantenerse, por lo menos, a nivel mundial. Como consecuencia de todo lo anterior, las empresas, se han hecho más difíciles de gestionar y dirigir. Consecuentemente, las necesidades y características que permiten a éstas mantenerse competitivas en sus mercados, están transformándose de manera radical.

Se requiere de una constante capacidad de adaptación al entorno, anticipándose a los cambios y previendo éstos con suficiente antelación; se requiere de una flexibilidad interna que sirva de ayuda y complemento de la capacidad de adaptación al entorno; ampliar la capacidad de innovación, tanto de productos como de procesos en el orden de estrategia permanente y como base de competitividad; generar una nueva visión del análisis de la cadena de valor agregado tanto a nivel de cliente interno y cliente externo; desarrollar nuevas capacidades y habilidades directivas que permitan el máximo y más eficiente aprovechamiento de los recursos; impulsar el uso adecuado de las tecnologías y de los sistemas de información o una máxima integración e implicación del personal en las actividades de la em- 
presa, se han convertido para muchas de ellas en una habilidad difícil de alcanzar por los competidores; un mayor desarrollo de las herramientas de gestión a todos los niveles y en todas las áreas de la empresa.

La gestión en este entorno requiere de administradores con valores e ideales humanos que jueguen un papel decisivo, deben entender las vastas implicaciones de sus actividades. El administrador es la persona responsable del desempeño eficiente de una organización, el uso adecuado de los recursos productivos: personas, maquinaria, materias primas, recursos financieros, etc., requiere espíritu empresarial y de competencias en, liderazgo, comunicación, innovación, trabajo en equipo; que haga de cabeza visible, de monitor, de portavoz, gestor de correctivos, asignador de recursos, negociador, solucionador de conflictos, tomador de decisiones, conocedor del sector, que desarrolle su potencial y habilidad mental, que posea elevados valores morales y éticos, orientado a la acción; debe ser ante todo un oyente de primera categoría, con una mente analítica y habilidad para integrar elementos diversos, con habilidades sociales, relacionista público, debe entender la gama infinita de temperamentos y humores del ser humano, tiene que desarrollar habilidades persuasivas.

La administración es una actividad cotidiana que exige trabajo sostenido y sistemático cada hora de cada día, su éxito radica en hacer las preguntas correctas y proporcionar las respuestas correctas a través del trabajo sistemático.

La atención del administrador se enfoca en objetivos, el autocontrol y el desempeño mejorado del conjunto, motiva a otros a que hagan su propia contribución, establece sus prioridades, la administración del tiempo es importantísima, es dinero, es una medida de esfuerzo, es un recurso no renovable; el administrador es un trabajador del conocimiento, identifica conocimientos y destrezas de su personal para sacar adelante los objetivos, mejora la comunicación, es selectivo en el aco-
La administración, a pesar de su importancia para el hombre, es una de las más ubicuas y difusas funciones en todas las sociedades, encontrándose en los hogares, iglesias, gobierno y empresas económicas de todos los pueblos. 
pio de información, acerca la planeación a la ejecución, tiene capacidad de análisis y toma razonada de decisiones, sabe desarrollar evaluación del desempeño realzando las fortalezas de las personas, sabe aprender y enseñar las claves de la eficacia, se anticipa y satisface los requerimientos de los clientes, sabe organizar el futuro para que compita con el presente, identifica las áreas críticas de supervivencia y crecimiento del negocio, logra identificar los factores invisibles de la productividad como conocimientos, habilidades, innovación, tiempo, estructura, estrategia, etc.; combina eficientemente los recursos disponibles para hacer frente a las necesidades del consumidor; sabe que el propósito de cualquier negocio es crear un cliente o usuario a partir de la conversión del conocimiento interno y externo, renovado, con la participación activa de los trabajadores en bienes o servicios que el cliente requiere y que en última instancia es el intercambio del conocimiento por dinero; tiene la habilidad de tomar control de un negocio mediocre y convertirlo en triunfador; sabe tratar a las personas con dignidad y respeto, supone que la gente tiene talento y desea trabajar, desarrolla el potencial humano, su conocimiento, habilidades, imaginación y el impulso en lograr la excelencia y la satisfacción en el trabajo; logra que un trabajador se comporte con el sentido de responsabilidad de un gerente mediante un diseño adecuado del puesto de trabajo, que ofrezca nuevos retos y oportunidades de mejorar la comprensión y la capacidad de pensar, ofrece información suficiente sobre el resultado del proceso y la posibilidad de aprendizaje mediante el uso más efectivo de sus propios conocimientos y destrezas; implanta programas de entrenamiento vitalicio enfocado principalmente a desarrollar métodos, instrumentos y mejores productos; genera estructuras organizacionales donde exista claridad de la tarea, economía de esfuerzo, motivación y orientación de las personas, se desarrolle una visión unificada para alcanzar los objetivos, facilite la especialización del trabajo, la toma de decisiones y la renovación de sí misma; que tenga habilidades de comunicación en términos de qué, cuánto, cuándo a quién y cómo decir; que dimensione el impacto del desempeño de una organización en la sociedad, la economía y en el individuo y para tal efecto establezca controles sobre la base de la medición: económicos, significativos, adecuados, oportunos y fáciles de entender; que sepa tomar decisiones tácticas o estratégicas evaluando los riesgos, la economía, la oportunidad y la limitación de los recursos escasos. El administrador debe ser el cerebro y el corazón de las organizaciones.

Aunque no se encuentra en posición de llevar a cabo reformas sociales, está consciente de los problemas y necesidades sociales y trata de contribuir en su solución.

Es interdisciplinario, multidisciplinario e incluso intradisciplinario, sabe realizar análisis financiero, evaluar el costo relativo y conoce el lucro que ofrecen los diferentes productos, domina técnicas de mercadeo, de sistemas, contables, 
de producción, jurídicas, de recursos humanos. Maneja y aplica conceptos de psicología, sociología, antropología, economía, ergonomía, ingeniería industrial y ciencias exactas. En una palabra, es integral.

Todo lo anterior implica en el momento actual, una formación a partir de un currículo integrado horizontal, vertical y transversal, cuya columna vertebral es el área de Administración orientada hacia «una educación pensada en términos de competencias como saber hacer en contexto, que ofrece un marco de referencia para trascender el énfasis en el aprendizaje de datos y hechos desarticulados, y proponer a la educación el reto de generar espacios en donde los estudiantes logren consolidar una base que les permita enfrentar de manera significativa diferentes situaciones... Entender el sentido de una idea y sus implicaciones, plantear argumentos pertinentes en pro o en contra de una afirmación, lanzarse a la crítica y proposición de alternativas pertinentes y válidas ante una situación, son exigencias de la sociedad contemporánea a quienes participan en ella. Esta misma sociedad exige, que sin perder de vista su dinámica y diversidad, se reconozcan procesos de participación fundamentales y comunes a los distintos escenarios de construcción social» (Mantilla, 2001).

Exige derribar «las barreras que impiden al estudiante acceder a nuevos niveles de formación de pensamiento (irreflexión, error, ignorancia, precipitación, compartimentación del saber, etc.), y las barreras que impiden al educador comprender por qué el educando no aprende o no progresa en su formación» (Universidad de La Salle, 2001).

Así mismo, es necesario centrarse en el aprendizaje, en la búsqueda y construcción del conocimiento y desarrollo de la autogestión de la propia formación.

También se requiere incorporar, entre otros, los siete saberes que Edgar Morin estima necesarios para la educación del futuro como son:

1. Las cegueras del conocimiento (la falta de preocupación de hacer conocer lo que es conocer).

2. Los principios del conocimiento pertinente.

3. La enseñanza de la condición humana.

4. La enseñanza de la identidad terrenal.

5. La enseñanza a enfrentar las incertidumbres.

6. La enseñanza de la comprensión.

7. La ética del género humano, que posibilite la ampliación de las fronteras del conocimiento (Morin, 1999). 


\section{Bibliografía}

George, Claude, Historia del pensamiento administrativo, Editorial Prentice Hall, 1974.

Mantilla, Magdalena, Subdirectora del ICFES, Revista Educación y Cultura No. 56, Marzo 2001, (Entrevista).

Morin, Edgar, Los siete saberes necesarios para la educación del futuro, Editorial Magisterio, UNESCO, 1999.

Taylor, Frederick, Management Científico, Prólogo de Antonio Serra Ramoneda, Editorial Orbis, 1984.

Universidad de La Salle, Modelo Formativo, Ediciones Unisalle, 3ª. Edición. Bogotá, D. C.

Urwick \& Brech, La bistoria del Management, Editorial Orbis, 1984. 